\title{
Influence of strontium on the cubic to ordered hexagonal phase transformation in barium magnesium niobate
}

\author{
M THIRUMAL and A K GANGULI* \\ Department of Chemistry, Indian Institute of Technology, New Delhi 110 016, India
}

MS received 5 June 2000

\begin{abstract}
Oxides of the type $\mathrm{Ba}_{3-x} \mathrm{Sr}_{x} \mathrm{MgNb}_{2} \mathrm{O}_{9}$ were synthesized by the solid state route. The $x=0$ composition $\left(\mathrm{Ba}_{3} \mathrm{MgNb}_{2} \mathrm{O}_{9}\right)$ was found to crystallize in a disordered (cubic) perovskite structure when sintered at 1000C. For higher Sr doping $(x \geq 0 \cdot 5)$, there was clearly the presence of an ordered hexagonal phase indicated by the growth of superstructure reflections in the powder $\mathrm{X}$-ray diffraction patterns. In all the compositions there was the presence of a minor amount of $\mathrm{Ba}_{5-x} \mathrm{Sr}_{x} \mathrm{Nb}_{4} \mathrm{O}_{15}$ phase which increased with $\mathrm{Sr}$ substitution up to $x=1$ and then it remained nearly constant at about $5 \%$. Samples sintered at $1300 \mathrm{C}$ showed the hexagonally ordered phase for the entire range of composition $(0 \leq x \leq 3)$. The degree of ordering being considerably greater than in the $1000 \mathrm{C}$ heated samples as evidenced by several superstructure reflections.
\end{abstract}

Keywords. Oxides; X-ray diffraction; ordering; dielectric materials.

\section{Introduction}

Among various families of oxides studied for the microwave dielectric applications, the oxides of the type $\mathrm{A}\left(\mathrm{B}_{1 / 3} \mathrm{~B}_{2 / 3}^{\prime}\right) \mathrm{O}_{3}$ have been particularly of interest. Oxides with $\mathrm{A}=\mathrm{Ba}, \mathrm{Sr} ; \mathrm{B}=\mathrm{Zn}, \mathrm{Mg}$ and $\mathrm{B}^{1}=\mathrm{Nb}$ and $\mathrm{Ta}$ have been found to have appropriate dielectric properties. $\mathrm{Ba}_{3} \mathrm{ZnTa}_{2} \mathrm{O}_{9}$ was first reported to show extremely low dielectric loss at microwave frequencies (Kawashima et al 1983). Several studies on related oxides have been carried out on other tantalates. $\mathrm{Ba}_{3} \mathrm{MgTa}_{2} \mathrm{O}_{9}$ has been studied extensively for its microwave properties (Nomura et al 1982; Desu and O'Bryan 1985; Vincent et al 1993). The $\mathrm{A}\left(\mathrm{B}_{1 / 3} \mathrm{~B}_{2 / 3}^{\prime}\right) \mathrm{O}_{3}$ or $\mathrm{A}_{3} \mathrm{BB}_{2}^{1} \mathrm{O}_{9}$ type of perovskite oxides were first prepared by Roy (1954) and Galasso et al (1959). These crystallize in a disordered cubic structure or in a hexagonally ordered structure. The ordered structure results from the $1: 2$ ordering of the $B$ and $B^{1}$-cations $\left(-\mathrm{B}-\mathrm{B}^{1}-\mathrm{B}^{1}-\mathrm{B}-\right)$ along the [111] direction of the cubic perovskite cell. It is now known that the B-site ordering has a significant influence on the dielectric loss at microwave frequencies.

BMT $\left(\mathrm{Ba}_{3} \mathrm{MgTa}_{2} \mathrm{O}_{9}\right)$ is disordered at low temperatures and becomes ordered at high temperatures (around 1600C) (Desu and O'Bryan 1985). Ordering is also influenced by the addition of small quantities of dopants such as $\mathrm{BaZrO}_{3}$ in $\mathrm{Ba}_{3} \mathrm{MgTa}_{2} \mathrm{O}_{9}$ (Tamura et al 1984). Compared to BMT, the niobium analogue $\mathrm{Ba}_{3} \mathrm{MgNb}_{2} \mathrm{O}_{9}$ (BMN) has been studied to a much lesser extent. It is

*Author for correspondence reported to have a hexagonally ordered perovskite structure (Galasso and Pyle 1963) when sintered at 1400C and its dielectric properties show comparatively higher losses than BMT (Nomura 1983). In our studies we decided to investigate the influence, if any, of A-site substitution on the B-site ordering in an attempt to obtain ordered perovskites at relatively low temperatures (1300C). Note that both BMN and SMN $\left(\mathrm{Sr}_{3} \mathrm{MgNb}_{2} \mathrm{O}_{9}\right)$ are reported to be hexagonally ordered at $1400 \mathrm{C}$. An earlier study (Onoda et al 1982) of a related system, $\mathrm{Ba}_{3-x} \mathrm{Sr}_{x} \mathrm{ZnNb}_{2} \mathrm{O}_{9}$, gives some evidence of the presence of ordered structures at high $\mathrm{Sr}$ concentration for samples sintered at 1500C. Recent studies on Sr-doping in $\mathrm{Ba}_{3} \mathrm{ZnNb}_{2} \mathrm{O}_{9}$ (Colla et al 1993) and $\mathrm{Ba}_{3} \mathrm{MgTa}_{2} \mathrm{O}_{9}$ (Sugiyama and Nagai 1993; Nagai et al 1997) have also shown the presence of a new type of ordering of the octahedras leading to a lower symmetry (monoclinic) for the Sr-rich phases.

We have synthesized solid solutions for the first time between $\mathrm{Ba}_{3} \mathrm{MgNb}_{2} \mathrm{O}_{9}-\mathrm{Sr}_{3} \mathrm{MgNb}_{2} \mathrm{O}_{9}$. In this paper we report the synthesis, structural studies and phase relations at $1000 \mathrm{C}$ and $1300 \mathrm{C}$.

\section{Experimental}

The starting materials were $\mathrm{BaCO}_{3}, \mathrm{SrCO}_{3}, \mathrm{MgO}$ and $\mathrm{Nb}_{2} \mathrm{O}_{5}$. Stoichiometric quantities were weighed, ground and calcined at $1000 \mathrm{C}$ for $30 \mathrm{~h}$ with two intermittent grindings. The calcined powder was ground, pressed into pellets with 5\% polyvinylalcohol (PVA) solution and at 4 ton pressure. These pellets were sintered at $1000 \mathrm{C}$ for 
$48 \mathrm{~h}$ followed by sintering at $1200 \mathrm{C}$ for $24 \mathrm{~h}$ and $1300 \mathrm{C}$ for $12 \mathrm{~h}$. Powder X-ray diffraction (PXRD) was carried out using a Scintag-XDS 3000 and Rigaku RU 200 DMax diffractometer with $\mathrm{Cu}-\mathrm{K} \alpha$ radiation. Lattice parameters were calculated by a least square fit to the observed $d$ values.

\section{Results and discussion}

Powder X-ray diffraction patterns for $\mathrm{Ba}_{3} \mathrm{MgNb}_{2} \mathrm{O}_{9}$ $(x=0.0)$ synthesized at $1000 \mathrm{C}$ could be indexed on a cubic unit cell. For the $x=0.5$ composition in $\mathrm{Ba}_{3-x} \mathrm{Sr}_{x} \mathrm{MgNb}_{2} \mathrm{O}_{9}$, we clearly see the growth of the superstructure line at $d \sim 5.0 \mathrm{~A}$ (figure 1) corresponding to the

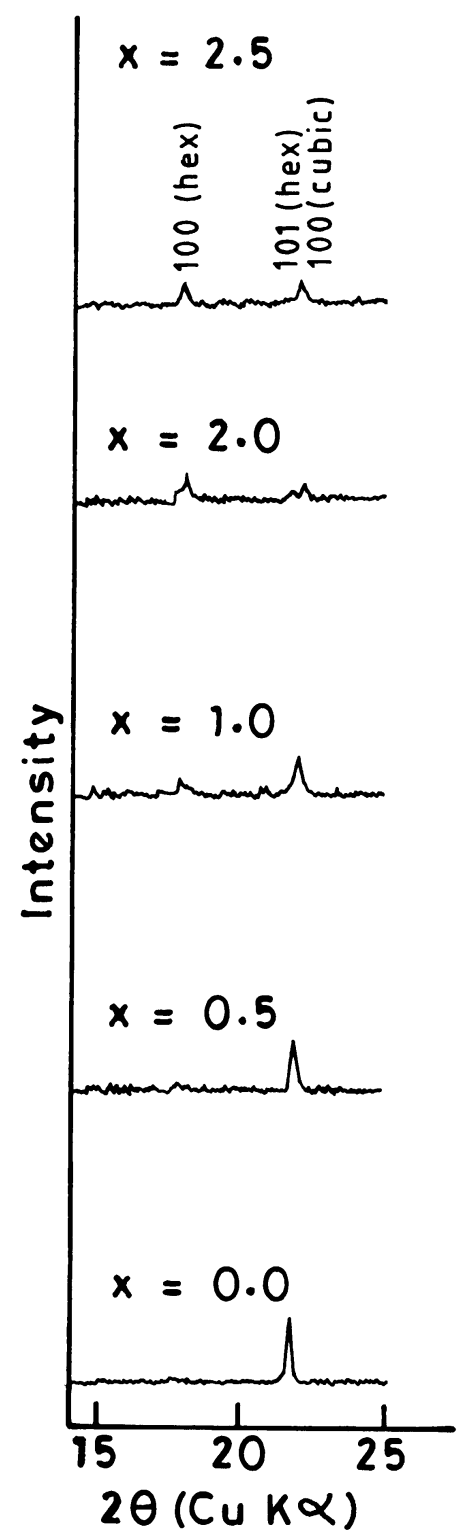

Figure 1. $\mathrm{XRD}$ of $\mathrm{Ba}_{3-x} \mathrm{Sr}_{x} \mathrm{MgNb}_{2} \mathrm{O}_{9}$ sintered at 1000C. (Note the increase in the intensity of the low $(100)_{\text {hex }}$ line with increase in $x$ ).
(100) reflection of the hexagonally $(1: 2)$ ordered structure. The other superstructure lines however are not observed clearly. The $(100)_{(\text {hex })}$ reflection grows in intensity with 'Sr' concentration and the $(100)_{\text {(cubic), which }}$ corresponds to the $(101)_{\text {(hex) }}$ reflection, decreases in intensity as is observed in hexagonally ordered structures. There is a gradual shift of the peaks towards higher $2 \theta$ indicating the gradual decrease in the lattice parameters on Sr-substitution.

A small amount $(5 \%)$ of a $\mathrm{Ba}_{5} \mathrm{Nb}_{4} \mathrm{O}_{15}$ related phase occurs in all the samples. There appears to be a shift towards lower $d$ values for this phase suggesting $\mathrm{Sr}$ doping in Ba sites in this impurity phase. Another cubic phase is present at higher $\mathrm{Sr}$ doping $(x \geq 1)$ and is a maximum $(\sim 15 \%)$ at $x=2$ (figure 2 ) after which it decreases. A close look at the $d$ values of the lines corresponding to the cubic impurity phase in the $x=1.0$ loaded composition suggests that this impurity phase might be of the type $\mathrm{Ba}_{3} \mathrm{Mg}_{1-x} \mathrm{Sr}_{x} \mathrm{Nb}_{2} \mathrm{O}_{9}$ since the reflections occur at higher $d$ values $(2.920,110)$ compared to the parent $\mathrm{Ba}_{3} \mathrm{MgNb}_{2} \mathrm{O}_{9}(2 \cdot 900,110)$ phase. This is possible only if the larger ion $\left(\mathrm{Sr}^{2+}\right)$ substitutes on the $\mathrm{Mg}^{2+}$ site. However there is a gradual shift to lower $d$ values with increase in $\mathrm{Sr}$ concentration. This could be explained if we consider

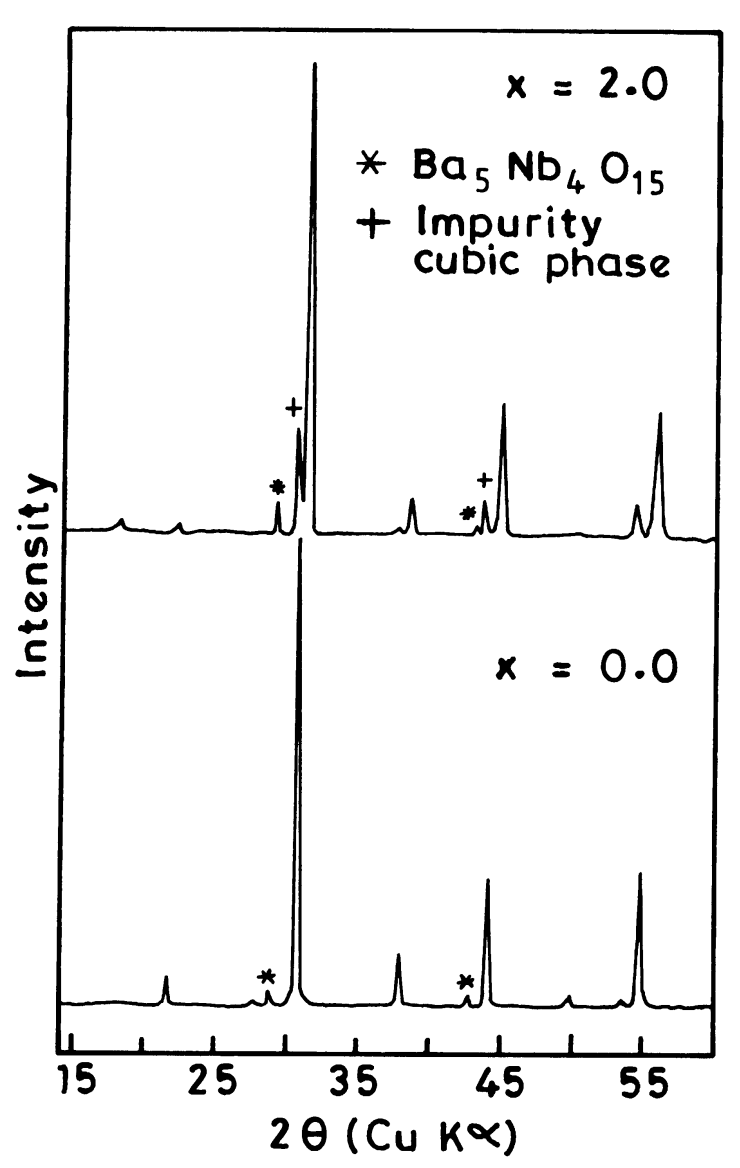

Figure 2. $\mathrm{XRD}$ of $\mathrm{Ba}_{3} \mathrm{MgNb}_{2} \mathrm{O}_{9}(x=0)$ and $\mathrm{BaSr}_{2} \mathrm{MgNb}_{2} \mathrm{O}_{9}$ $(x=2 \cdot 0)$ sintered at $1000 \mathrm{C}$. 
Sr also substitutes on the Ba site at higher Sr concentration in addition to initially substituting on the $\mathrm{Mg}$ sites. This impurity phase would thus belong to a family of the type $\mathrm{Ba}_{3-x} \mathrm{Sr}_{x} \mathrm{Mg}_{1-y} \mathrm{Sr}_{y} \mathrm{Nb}_{2} \mathrm{O}_{9}$.

The $\mathrm{Ba}_{3-x} \mathrm{Sr}_{x} \mathrm{MgNb}_{2} \mathrm{O}_{9}$ compositions when further sintered at $1300 \mathrm{C}$ were found to have the $1: 2$ ordered structure for the entire range of composition $(0 \leq x \leq 3)$ and the powder X-ray diffraction patterns (figure 3 ) can be indexed on a hexagonal cell. A small amount (5-10\%) of $\mathrm{Ba}_{5} \mathrm{Nb}_{4} \mathrm{O}_{15}$ related phase persists in all the compositions as earlier found in the $1000 \mathrm{C}$ heated samples. The $x=0$ composition, $\mathrm{Ba}_{3} \mathrm{MgNb}_{2} \mathrm{O}_{9}$ also shows additional weak peaks $(5 \%)$ corresponding to $\alpha-\mathrm{Ba}_{4} \mathrm{Nb}_{2} \mathrm{O}_{9}$ (figure 3 ). However there are no extra peaks corresponding to the minor cubic phase tentatively ascribed to the formula $\mathrm{Ba}_{3-x} \mathrm{Sr}_{x} \mathrm{Mg}_{1-y} \mathrm{Sr}_{y} \mathrm{Nb}_{2} \mathrm{O}_{9}$ as found in the 1000C heated samples. The oxides at $1300 \mathrm{C}$ are clearly more ordered as evidenced from a large number of superstructure reflections (figure 3 ) compared to the corresponding compositions heated at $1000 \mathrm{C}$ where only the (100) reflection of the hexagonally ordered structure is observed (figures 1 and 2). The lattice parameters of $\mathrm{Ba}_{3} \mathrm{MgNb}_{2} \mathrm{O}_{9} \quad(\mathbf{a}=$ $5 \cdot 800(4), \mathbf{c}=7 \cdot 090(3))$ and $\mathrm{Sr}_{3} \mathrm{MgNb}_{2} \mathrm{O}_{9} \quad(\mathbf{a}=5 \cdot 681(2)$, $\mathbf{c}=6.942(1))$ are close to those reported earlier (Galasso and Pyle 1963). Table 1 shows the indexed diffraction pattern for an ordered hexagonal phase. The hexagonal lattice parameters show a decrease with an increase in the Sr content (figure 4). This decrease in lattice parameter can be attributed to the smaller size of $\mathrm{Sr}^{2+}$ ion (ionic radii

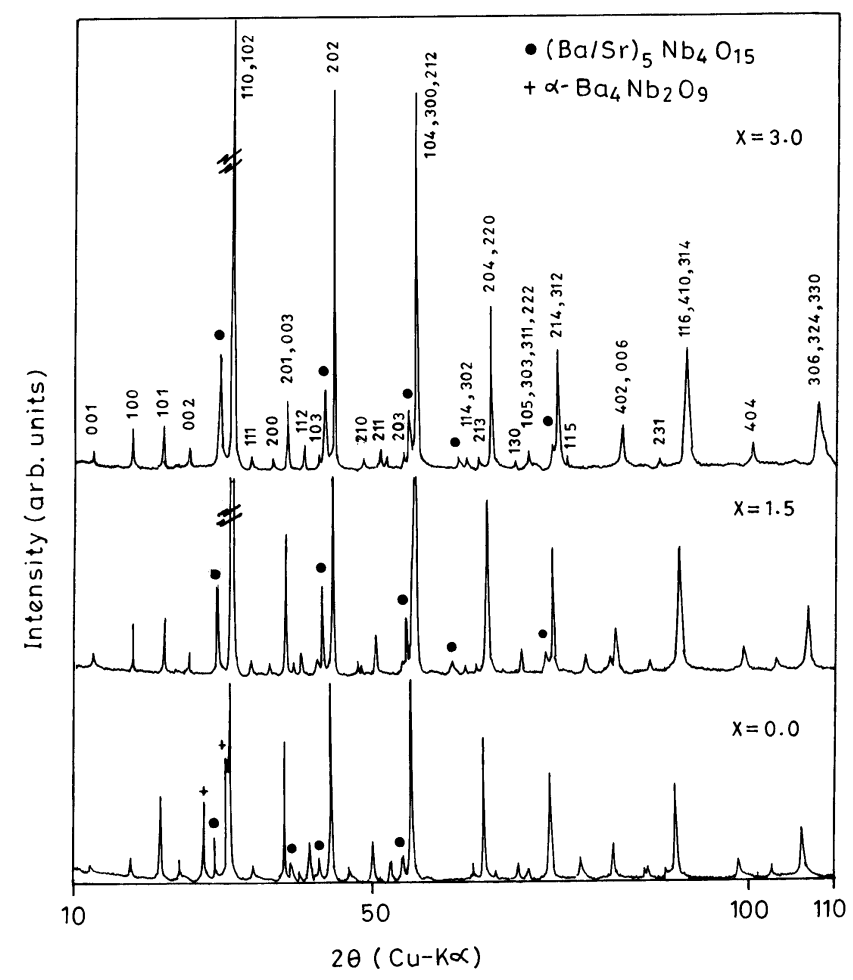

Figure 3. XRD pattern of $\mathrm{Ba}_{3} \mathrm{MgNb}_{2} \mathrm{O}_{9}, \mathrm{Ba}_{1.5} \mathrm{Sr}_{1.5} \mathrm{MgNb}_{2} \mathrm{O}_{9}$ and $\mathrm{Sr}_{3} \mathrm{MgNb}_{2} \mathrm{O}_{9}$ sintered at $1300 \mathrm{C}$. of $\mathrm{Ba}^{2+}$ (XII) is 1.61 and for $\mathrm{Sr}^{2+}$ (XII) is 1.44). In an earlier study (Onoda et al 1982) on the related $\mathrm{Ba}_{3-x} \mathrm{Sr}_{x} \mathrm{ZnNb}_{2} \mathrm{O}_{9}$ system (sintered at $1500 \mathrm{C}$ for $1 \mathrm{~h}$ ) there is evidence for ordering with increase in $\mathrm{Sr}$ concentration (for $x \geq 0 \cdot 8$ ) into $1: 2$ type hexagonally ordered perovskite from the broadening of high angle lines in the X-ray diffraction pattern. This value of $x$ is close to what we also observe $(x \geq 0 \cdot 5)$ in our studies on $\mathrm{Ba}_{3-x} \mathrm{Sr}_{x} \mathrm{MgNb}_{2} \mathrm{O}_{9}$. However, we observe ordering behaviour at temperatures as low as $1000 \mathrm{C}$ whereas the $\mathrm{Zn}$ analogue was sintered at 1500C (Onoda et al 1982). The broad lines observed in the earlier study (Onoda et al 1982) indicate the presence

Table 1. Indexed $\mathrm{X}$-ray powder diffraction pattern of $\mathrm{Ba}_{1.5} \mathrm{Sr}_{1.5} \mathrm{MgNb}_{2} \mathrm{O}_{9}$ (1300C) indexed on a hexagonal cell, $a=5.748(2) \AA, c=7 \cdot 0299(7) \AA$ unindexed lines belong to $(\mathrm{Ba} / \mathrm{Sr})_{5} \mathrm{Nb}_{4} \mathrm{O}_{15}$.

\begin{tabular}{|c|c|c|c|}
\hline$d$ (obs) & $d(\mathrm{cal})$ & $I / I_{0}$ & $h k l$ \\
\hline $7 \cdot 104$ & $7 \cdot 030$ & 2 & 001 \\
\hline 4.993 & 4.978 & 4 & 100 \\
\hline $4 \cdot 074$ & $4 \cdot 063$ & 4 & 101 \\
\hline $3 \cdot 531$ & $3 \cdot 515$ & 2 & 002 \\
\hline $3 \cdot 071$ & - & 11 & - \\
\hline $2 \cdot 878$ & $2 \cdot 871,2 \cdot 874$ & 100 & 102,110 \\
\hline $2 \cdot 657$ & $2 \cdot 660$ & 1 & 111 \\
\hline $2 \cdot 486$ & $2 \cdot 489$ & 1 & 200 \\
\hline $2 \cdot 345$ & $2 \cdot 346,2 \cdot 343$ & 10 & 201,003 \\
\hline $2 \cdot 288$ & - & 1 & - \\
\hline $2 \cdot 226$ & $2 \cdot 225$ & 2 & 112 \\
\hline $2 \cdot 125$ & $2 \cdot 120$ & 1 & 103 \\
\hline $2 \cdot 095$ & - & 6 & - \\
\hline $2 \cdot 032$ & $2 \cdot 031$ & 30 & 202 \\
\hline $1 \cdot 899$ & & 1 & - \\
\hline $1 \cdot 877$ & $1 \cdot 881$ & 1 & 120 \\
\hline $1 \cdot 814$ & $1 \cdot 816,1 \cdot 816$ & 3 & 113,211 \\
\hline 1.707 & 1.706 & 1 & 203 \\
\hline $1 \cdot 691$ & - & 4 & - \\
\hline $1 \cdot 657$ & $1.659,1.657,1.659$ & 28 & $300,104,212$ \\
\hline $1 \cdot 534$ & - & 1 & - \\
\hline 1.499 & $1 \cdot 499,1 \cdot 500$ & 1 & 114,302 \\
\hline 1.467 & 1.467 & 1 & 213 \\
\hline 1.436 & $1.436,1.437$ & 12 & 204,220 \\
\hline $1 \cdot 352$ & $1 \cdot 353,1 \cdot 354,1 \cdot 355$ & 2 & $105,303,311$ \\
\hline $1 \cdot 298$ & $1 \cdot 285$ & 2 & 132 \\
\hline $1 \cdot 284$ & $1 \cdot 284$ & 9 & 124 \\
\hline $1 \cdot 224$ & $1 \cdot 224,1 \cdot 225,1 \cdot 225$ & 2 & $205,223,401$ \\
\hline $1 \cdot 182$ & $1 \cdot 190$ & 1 & 133 \\
\hline $1 \cdot 181$ & - & 1 & - \\
\hline $1 \cdot 176$ & - & 1 & - \\
\hline $1 \cdot 172$ & $1 \cdot 173$ & 3 & 402 \\
\hline $1 \cdot 169$ & $1 \cdot 172$ & 2 & 006 \\
\hline $1 \cdot 124$ & $1 \cdot 126,1 \cdot 127$ & 1 & 125,231 \\
\hline 1.094 & 1.099 & 1 & 403 \\
\hline $1 \cdot 091$ & - & 1 & - \\
\hline 1.085 & $1.085,1.086,1.086,1.086$ & 9 & $116,134,232,140$ \\
\hline $1 \cdot 015$ & $1 \cdot 016$ & 2 & 404 \\
\hline $1 \cdot 013$ & $1.004,1.005$ & 1 & 007,225 \\
\hline $0 \cdot 984$ & $0.984,0.985,0.986,0.986$ & 1 & $107,135,143,501$ \\
\hline $0 \cdot 961$ & 0.959 & 1 & 502 \\
\hline 0.958 & $0.958,0.958$ & 3 & 234,330 \\
\hline $0 \cdot 956$ & $0 \cdot 957$ & 5 & 306 \\
\hline 0.954 & 0.949 & 3 & 331 \\
\hline
\end{tabular}




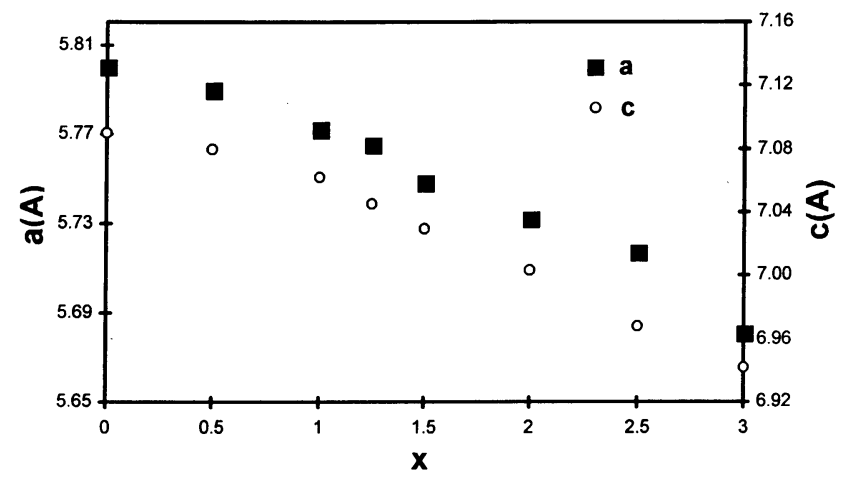

Figure 4. Plot of the variation of the hexagonal lattice parameters with $\mathrm{Sr}$ concentration $(x)$ for samples sintered at 1300C.

of both ordered and disordered phase coexisting together, whereas, in our investigations of the 1300C sintered phases we clearly observe sharp lines including all superstructure reflections indicating a purely hexagonal structure. The transformation from a purely cubic structure to an ordered structure is usually influenced by the size and charge difference of the $\mathrm{B}$ and $\mathrm{B}^{1}$ ions in the $\mathrm{A}_{3} \mathrm{BB}_{2}^{1} \mathrm{O}_{9}$ type of oxides and to a much lesser extent by A-site substitution. We have tried to look for any lower symmetry reflections in our X-ray diffraction patterns corresponding to the monoclinic superstructure reported for the $\mathrm{Sr}$-doped $\mathrm{Ba}_{3} \mathrm{MgTa}_{2} \mathrm{O}_{9}$ and $\mathrm{Ba}_{3} \mathrm{ZnNb}_{2} \mathrm{O}_{9}$ phases (Colla et al 1993; Sugiyama and Nagai 1993). The weak superstructure lines could not be clearly ascertained due to the presence of $(\mathrm{Ba} / \mathrm{Sr})_{5} \mathrm{Nb}_{4} \mathrm{O}_{15}$ type of phases in the Sr-doped $\mathrm{Ba}_{3} \mathrm{MgNb}_{2} \mathrm{O}_{9}$ system studied by us.

\section{Conclusions}

Various members of $\mathrm{Ba}_{3-x} \mathrm{Sr}_{x} \mathrm{MgNb}_{2} \mathrm{O}_{9}$ family were synthesized by the normal solid state method. There is a clear growth of the hexagonally ordered perovskite phase for those compositions with $x \geq 0.5$ at $1000 \mathrm{C}$ evidenced by the presence of one superstructure line in the powder Xray diffraction patterns of the $1000 \mathrm{C}$ heated samples. Thus Sr substitution helps in obtaining ordered structures at low temperature $(1000 \mathrm{C})$. At $1300 \mathrm{C}$ the entire range of oxides $(0 \leq x \leq 3)$ are fully ordered as observed by powder X-ray diffraction and can be indexed satisfactorily to a hexagonal cell. There are two impurity phases present at $1000 \mathrm{C}$, a $\mathrm{Ba}_{5-x} \mathrm{Sr}_{x} \mathrm{Nb}_{4} \mathrm{O}_{15}$ type and another cubic phase (possibly of the type $\mathrm{Ba}_{3-x} \mathrm{Sr}_{x} \mathrm{Mg}_{1-y} \mathrm{Sr}_{y} \mathrm{Nb}_{2} \mathrm{O}_{9}$ ). At $1300 \mathrm{C}$ this impurity cubic phase disappears although the presence of the $\mathrm{Ba}_{5-x} \mathrm{Sr}_{x} \mathrm{Nb}_{4} \mathrm{O}_{15}$ type phase ( 5\%) seems to persist in all samples.

We thus conclude that at temperatures of $1000 \mathrm{C}, \mathrm{Sr}$ predominantly substitutes the A-site of the $A\left(B_{1 / 3} B_{2 / 3}^{1}\right) O_{3}$ structure, although a small fraction does substitute the Bsite (giving the impurity cubic phase). At $1300 \mathrm{C}$ only the A-site is substituted resulting in the absence of the cubic phase of the type $\mathrm{Ba}_{3-x} \mathrm{Sr}_{x} \mathrm{Mg}_{1-y} \mathrm{Sr}_{y} \mathrm{Nb}_{2} \mathrm{O}_{9}$.

\section{Acknowledgements}

Financial assistance to AKG from BRNS (DAE), Mumbai, is gratefully acknowledged.

\section{References}

Colla E L, Reaney I M and Setter N 1993 J. Appl. Phys. 74 3414

Desu S B and O'Bryan H M 1985 J. Am. Ceram. Soc. 68546

Galasso F and Pyle J 1963 J. Phys. Chem. 671561

Galasso F, Katz L and Ward R L 1959 J. Am. Chem. Soc. 81 820

Kawashima S, Nishida M, Ueda I and Ouchi H $1983 \mathrm{~J}$. Am. Ceram. Soc. 66421

Nagai T, Sugiyama M, Sando M and Niihara K 1997 Jpn J. Appl. Phys. 361146

Nomura S 1983 Ferroelectrics 4961

Nomura S, Toyama K and Kaneta K 1982 Jpn J. Appl. Phys. 21 L624

Onoda M, Kuwata J, Kaneta K, Toyama K and Nomura S 1982 Jpn J. Appl. Phys. 211707

Roy R 1954 J. Am. Ceram. Soc. 27581

Sugiyama M and Nagai T 1993 Jpn J. Appl. Phys. 324360

Tamura H, Konoike T, Sakabe Y and Wakino K 1984 J. Am. Ceram. Soc. 67 C-59

Vincent H, Perrier C, Theritier P and Labeyrie M 1993 Mater. Res. Bull. 28951 